\title{
Surviving hurricane Wilma
}

Patrick Tansley

J R Soc Med 2006;99:427-428

I am a surgical registrar, but on holiday last year I became a physician, trauma doctor, environmental health officer and leader. I was glad of a comprehensive medical training and hope that my story will both entertain and be to help those finding themselves in similarly demanding circumstances.

My wife and I had spent almost 2 weeks in Cancun in October 2005. Hurricane Wilma, the third category five Atlantic hurricane of the year, more powerful than Katrina, struck just prior to our scheduled departure. ${ }^{1}$ We were told by telephone to evacuate and for the first time became refugees. We were taken to a 'hurricane-proof' shelter, a massive conference centre comprising two carpeted floors each greater in size than a football pitch and divided into an inner citadel and surrounding lobby. Partitions subdivided the inner areas, each filled with sun-loungers for beds. The shelter was filled with 3500 other holiday-makers/refugees of all ages and conditions, two-thirds American, the rest mostly British. All except one exit was sealed shut-we could not see out, there was no daylight and we had no idea what was outside.

Anxiety quickly replaced the initial atmosphere of adventure. People suffered claustrophobia and formed queues at the only exit to glimpse outside. The car park was a maelstrom of rain driven by $185 \mathrm{mph}$ winds. Despite storm shutters, windows blew in showering us with glass and water. Power and communications were lost. Running water ceased along with the air conditioning and ventilation. Ceilings caved in, water poured across carpeted floors and had to be collected manually to flush nonfunctioning toilets.It was obvious that without sanitation spreading disease would be inevitable. People walked barefoot from flooded toilets onto wet carpets, which quickly began to smell. Without washing their hands, people served food using communal utensils. Parents allowed children to play on broken glass, unaware of hazards and not appreciating the gravity of our situation. Rumours circulated that another shelter had collapsed with loss of life, causing further anxiety. Lack of communication meant we had no way of confirming events or whether the outside world knew of our predicament.

Department of Plastic and Reconstructive Surgery, Mount Vernon Hospital, Middlesex, London HA6 2RN, UK

E-mail: patrick.tansley@btinternet.com
The situation became so intolerable that I decided to take action to try to avert a medical catastrophe. Addressing the 1750 refugees on each floor I was suddenly thankful for my public speaking experience. Using a megaphone, I emphasized the threat of gastrointestinal and pulmonary disease. The need for hydration rather than food was stressed and a regime instituted whereby food would only be served by chefs to prevent excessive eating and crosscontamination. Sentries were placed at the entrance to the only working toilets, to enforce hygiene restrictions and distribute rainwater for flushing. Entry without footwear was forbidden and hand disinfection made mandatory using paper towels soaked in dilute bleach. Everyone was instructed to keep mobile to avoid chest infections. I had no idea how I would be received, as I was simply another refugee, without authority, trying to use the principles of my medical training. However, people seemed relieved to have someone willing to take charge and the instructions were greeted well. This taught me a valuable lesson about leadership _ even though it can seem a formidable challenge to address so many and offer them little but hardship, people will follow a simple, sensible message.

I cannot adequately describe the relief at breathing fresh air and seeing beyond the shelter's walls when eventually the winds reduced sufficiently for us to venture outside. Surrounded by devastation, fear then turned to frustration at the lack of information. Communication was nonexistent and we did not know if efforts were being made to get us out, especially following the Katrina debacle. ${ }^{2}$ We were informed that Cancun's infrastructure had been destroyed; telecommunication masts were gone, roads blocked, the airport unusable and martial law imposed. Thus began the next phase. We had survived Wilma but now needed to get out of the country along with 70000 other tourists.

In the shelter, significant events unfolded later the same day. An infant became gravely ill making everyone uneasy and, simultaneously, it was determined that the little information we had about possible evacuation was spurious. We were therefore on our own with no foreseeable prospects of rescue. This knowledge precipitated a seismic change in attitudes. At last, the listening masses seemed to grasp the seriousness of the situation. An emergency plan was established by a refugee who had some training in disaster management. Everyone was requested to 
contribute to five activities comprising: medical and hygiene; engineering and construction; communications, logistics and security; food and health; maintaining calm and children's entertainment.

What followed within hours was an incredible transformation of the shelter from a squalid rabble of individuals into a cohesive working organization focused on health, construction and evacuation. I have never seen so many people with a common cause develop into a team as effectively as I did that morning. Doctors, nurses, paramedics, pharmacists, plumbers, electricians, child-care assistants and teachers came forward. Construction workers gutted the shelter - sodden carpets were torn up along with the partitions that had prevented ventilation. Floors and toilets were scrubbed with bleach. The shelter was turned into a vast, clean open space and a children's play area established outside. I set up a field hospital with medical staff organized on a rota system. The hotel's medical supplies were requisitioned and a public appeal made for personal medications. Our facilities included triage, trauma, adult and paediatric areas and a pharmacy.

I was immensely glad of my broad training, for I was required to manage a breadth of clinical problems. Trauma was my greatest concern, due to our very limited equipment. A single venflon was all we had for a week and was reserved to manage any life-threatening incident. When the ceiling caved in, a young man sustained a closed fracture of his right arm that required splinting. A roofer who sustained head injuries when knocked unconscious by masonry caught in the wind recovered well under simple neurological observation. Infants and adults with gastroenteritis were successfully managed with oral fluid rehydration containing added sugar. Verbal reassurance and the judicious use of benzodiazepines were used to manage stress-induced psychiatric difficulties. International assistance through the British Embassy was sought to acquire immunosuppressive medications for a renal transplant. Other problems tested us, such as fights following consumption of hidden alcohol. Negotiation in conjunction with the threat of summoning British military assistance through Foreign Office channels quelled the situation. With a story to tell, I was eventually interviewed by BBC journalists for UK radio and TV news bulletins. Dressed in a T-shirt and shorts and sporting the longest stubble I had ever worn, I must have looked rather comical as the lead doctor.

The sights on our eventual departure offered vivid insight into the forces of nature that had ranged against us. Reinforced concrete power lines had simply snapped. Steel road-sign gantries were twisted through right angles. Buildings and vehicles were destroyed and roads flooded. It became clear that although we had endured an arduous time, we had also benefited from a valuable experience with important lessons. Overnight, we had gone from hotel luxury to total captivity in appallingly unsanitary conditions. People were filthy; some behaved well, others less so. We saw the best and worst of human nature. As individuals we had to make use of medical training, self-reliance and leadership. Humour was invaluable in the darker moments. As a group, all nationalities had to get along and work together, being resourceful, minimizing risk and surviving. The environmental measures instituted seemed to offer some protection and may have contributed to the survival of the most vulnerable. I would encourage any doctor placed in a similar predicament to be confident in their abilities and instil that confidence in others. The experience I gained in handling difficult situations involving large numbers of people under stress was invaluable.

\section{Competing interests None declared.}

\section{REFERENCES}

1 Hurricane Wilma [http://en.wikipedia.org/wiki/Hurricane_Wilma] Accessed 4 February 2006

2 NMA calls response to Hurricane Katrina a "national disgrace". J Natl Med Assoc 2005;97:1334-5 